\title{
Medicine's metaphysical morass: how confusion about dualism threatens public health
}

\author{
Diane O'Leary $^{1}$ (1)
}

Received: 19 July 2019 / Accepted: 10 September 2020 / Published online: 24 September 2020

c) Springer Nature B.V. 2020

\begin{abstract}
What position on dualism does medicine require? Our understanding of that question has been dictated by holism, as defined by the biopsychosocial model, since the late twentieth century. Unfortunately, holism was characterized at the start with confused definitions of 'dualism' and 'reductionism', and that problem has led to a deep, unrecognized conceptual split in the medical professions. Some insist that holism is a nonreductionist approach that aligns with some form of dualism, while others insist it's a reductionist view that sets out to eradicate dualism. It's important to consider each version. Nonreductive holism is philosophically consistent and clinically unproblematic. Reductive holism, however, is conceptually incoherent-yet it is the basis for the common idea that the boundary between medical and mental health disorders must be vague. When we trace that idea through to its implementation in medical practice, we find evidence that it compromises the safety of patient care in the large portion of cases where clinicians grapple with diagnosis at the boundary between psychiatry and medicine. Having established that medicine must embrace some form of nonreductionism, I argue that Chalmers' naturalistic dualism is a stronger prima facie candidate than the nonreductive alternatives. Regardless of which form of nonreductionism we prefer, some philosophical corrections are needed to give medicine a safe and coherent foundation.
\end{abstract}

Keywords Dualism · Holism · Biopsychosocial model · Philosophy of medicine · Philosophy of psychiatry $\cdot$ Bioethics

Diane O'Leary

drdianeoleary@gmail.com

1 Rotman Institute of Philosophy, Western University, Western Interdisciplinary Research Building, 738, 1151 Richmond St. North, London, ON N6A 5B7, Canada 


\section{Part 1: Medical holism and its philosophically confusing claims}

Something appears to be seriously amiss in the practice of medicine! (Huth 1981, p. 247)

\subsection{The development of holism}

In the 1970s and 1980s, physicians, psychiatrists, ethicists, and philosophers came together in recognition of a problem. For centuries medical science had proceeded as a mechanistic sort of endeavor. Doctors' focal concern through this model had been the body and its diseases, with a sense that disease can best be remedied through a piecemeal approach to the body's parts. Through this "biomedical model" (BMM), medicine aimed for the kind of objectivity that generally characterizes the sciences, but in the late twentieth century that approach faced a reckoning. In spite of the undeniable success of the BMM at improving and protecting health, both professional and popular culture came to see that something was missing. Medicine's exclusive focus on the body had encouraged doctors to treat patients as things. The problem, it became clear, was that medicine should not be focused on the body. It should be focused on the person.

Widespread recognition of this problem created a "quality-of-care crisis" (Marcum $2008 \mathrm{a}$, p. v). On the moral side the crisis was addressed with the movement of "humanism", championed by Pellegrino and Thomasma (1981). By failing to recognize the person, rather than the body, as its chief concern, "modern medical care conceals a dangerous ethic that encourages treating persons as [objective] things" (Thomasma 2002, p. 335)". Humanism developed to address that problem, and its impact has been immense. Medical education, for example, now routinely includes humanities education. More importantly, humanism's central insights led to the development of bioethics as we know it today (Marcum 2008a, b). We owe our current understanding of informed consent, for example - along with all four of the now classic principles of clinical ethics - to the continued relevance of humanism's foundations in the 70s and 80s. Indeed, the largest conference for bioethicists in the US at this time is the annual meeting of the "American Society for Bioethics and Humanities".

In addition to the ethical concerns of humanism, objections to the BMM in the late twentieth century often took on a metaphysical character, and when they did, "holism", rather than "humanism", provided the remedy. From many perspectives humanism and holism are indistinguishable, and both terms have been used so loosely that distinct definitions are truly impossible. Still, it's safe to say that while humanism is generally understood to be concerned with ethical gaps in the BMM, holism set out at the start to rectify more abstract forms of misunderstanding. Though, as we will see, medical holism lacks a coherent definition, generally speaking a holistic position adjusts typical understanding of disparate elements in a way that allows us to see them as unified.

The central spokesperson for holism at its origins was George Engel, a psychiatrist whose work remains as influential today as it was in his own time. Based on a sense that "appeals to humanism" are "ephemeral and insubstantial... when not based on rational 
principles" (Engel 1977, p. 135), Engel dug into the conceptual misunderstanding that had led to dogmatic acceptance of the BMM.

I contend that all medicine is in crisis and, further, that medicine's crisis derives from the same basic fault as psychiatry's, namely, adherence to a model of disease no longer adequate for the scientific tasks and social responsibilities of either medicine or psychiatry... The biomedical model not only requires that disease be dealt with as an entity independent of social behavior, it also demands that behavioral aberrations be explained on the basis of disordered somatic...processes. Thus the biomedical model embraces...reductionism, the philosophic view that complex phenomena are ultimately derived from a single primary principle... (Engel 1977, p. 129).

To resolve this conceptual problem, Engel proposed that we replace the reductive "biomedical model" with a holistic "bio-psycho-social model" (BPSM). ${ }^{1}$ Based on biological systems theory, the BPSM offers a hierarchical explanatory perspective, so that we no longer limit the focus of medicine to the biological elements of disease. Instead, "clinicians must attend simultaneously to the biological, psychological, and social dimensions of illness" (Borrell-Carrio et al. 2004, p. 576). In addition, "the biopsychosocial model protests against the manner by which only non-subjective qualities gain explanatory power in analysing, diagnosing and treating somatic and mental health issues." (Schillmeier 2019, p. 1). It is a core tenet of holism that medical science will fail to accomplish its scientific and ethical goals if it fails to take stock of patients' subjective experiences as persons.

It's hard to overstate the value or historical importance of these insights. Engel's brand of holism had such a powerful impact on the profession that it's become central to medicine's identity in our time. The BPSM has been described as "the official philosophy of the American Psychiatric Association and the Diagnostic and Statistical Manual, DSM-5" (Rease 2014, p. 1). We see it in the World Health Organization's continued commitment to a definition of health as "a state of complete physical, mental and social well being, and not merely the absence of disease or infirmity" (WHO 2019). Indeed, it seems clear that Engel's ideas have been powerful enough to seep out from professional discourse into the mainstream, where the notion of "integrated mind-body medicine" is now an everyday feature of popular culture.

\subsection{The morass: holism's confusing claims}

From a metaphysical standpoint, it seems the chief insight of Engel's holism is straightforward: medicine should reject reductive physicalism in favor of a perspective that recognizes the existence and importance of the mind (or mental properties) (BorrellCarrio et al. 2004; Marcum 2008a, b; Woods 2015). What position on mind does holism propose, exactly? That question is challenging enough on purely philosophical grounds, and I will address it in Part 4. Unfortunately, Engel used basic philosophical

\footnotetext{
1 The form of holism I'm concerned with in this paper can be traced in a historical line from the 1970s into the present. This is distinct from "the new holism" of P4 systems medicine, which is ably summarized and critiqued by Vogt et al. (2016).
} 
terms in confusing and inaccurate ways, and this has led to conceptual complications that we must first consider:

...the biomedical model embraces both reductionism, the philosophic view that complex phenomena are ultimately derived from a single primary principle, and mind-body dualism, the doctrine that separates the mental from the somatic (Engel 1977, p. 130).

Not once, but consistently throughout all of Engel's writings, biological reductionism is directly equated with mind-body dualism:

The biomedical model can make provision neither for the person as a whole nor for data of a psychological or social nature. For the reductionism and mind-body dualism upon which the model is predicated requires that these must first be reduced to physico-chemical terms before they can have meaning (Engel 1981, p. 103).

Philosophically speaking, dualism and reductionism are diametrically opposed, so for philosophers it's hard to understand even what Engel means to say in these passages. It would be pleasant enough to let go of the effort to sort that out, but the confusions built into holism's original characterization have now become pervasive throughout the medical professions:

...the Cartesian division of the person into mind and body...is basic to the reductionist approach of medicine and therefore the source of its tendency to ignore the human dimensions of health and disease (Sullivan 1986, p. 331).

...to reject dualism is, on the face of it, to leave open the possibility that the mind can have a more significant role in illness, and in healthcare, than medicine has traditionally envisaged (Paley 2000, p. 1294).

Dualism...discounts the significance of mental states in the maintenance of health (Gendle 2016, p. 141).

The Cartesian notion of mind and body as two completely different substances has been indicated as the source of the medical reductionist view of the human being (Arnaudo 2017, p. 1082).

If this were just a confusing strain of armchair philosophy, nothing much would hang on the question of what these claims are intended to communicate. The mind-body problem is difficult, and it's not uncommon for professionals outside of philosophy to discuss the issue in a way that misunderstands basic terms and concepts.

But this is not just armchair philosophy. The World Health Organization and the American Psychiatric Association have based their goals and conclusions on the conceptual foundation of holism. More than that, in the realm of everyday medical practice the influence of the BPSM has been so strong that "rejection of biopsychosocial medicine is tantamount to a betrayal of one's profession" (Howsepian 1977, p. 179). In spite of the development of evidence-based medicine and its unequivocally biological orientation, the BPSM is still "woven into the delivery of care at every level, including insurance and hospital inpatient and outpatient services" (Greenfield 2007). To the extent that Engel was right- that is, to the extent that we can optimally improve 
health only with attention to both mind and body-it seems straightforwardly threatening for the profession to embrace an incoherent position on dualism. What are the WHO, the APA and the everyday practice of medicine actually doing when they set out to "do away with the reductionism and mind-body dualism inherent in the biomedical model" (Easton 1982, p. 1185)?

Something is indeed amiss in the practice of medicine. In what follows, however, I will not argue that holism is irretrievably confused in itself. On the contrary, I hope to show how medicine's struggle to articulate a consistent position on the mind arises from deep philosophical tension between its commitment to improving experience and its commitment to science.

I begin in Part 2 by pinning down terminological confusions that have led to incoherence in statements about mind and body in medicine. When we rectify those we see the sense in holism's confusing claims, but problems persist because holism maintains contradictory positions on reductionism. In Part 3, I show that while the nonreductive strand of holism is philosophically and clinically sound, reductive holism is conceptually incoherent. More importantly, reductive holism drives the clinical recommendation of deliberate diagnostic vagueness with patients whose symptoms might be diagnosed as either psychiatric or biomedical. Evidence suggests this recommendation leads to delayed diagnosis and treatment for substantial patient groups. Finally, having established that medicine must embrace some form of nonreductionism, I argue in Part 4 that Chalmers' naturalistic dualism is a stronger prima facie candidate for medicine's metaphysical foundation than the nonreductive alternatives. I conclude with a list of corrections needed to give medical holism a safe, coherent philosophical foundation.

\section{Part 2: Diagnosing the problem}

The more one looks at twentieth-century holism, the more elusive it becomes, the more it dissolves and reconfigures itself into its opposite (Rosenberg 2007, p. 155).

\subsection{Conflation of methodological reduction with ontological reduction}

Medical writing about holism uses central terms differently from the way that philosophers use them. First, philosophers draw a basic distinction between methodological reduction and ontological reduction. In research on holism, however, that distinction is rarely acknowledged.

When it comes to methodological reduction, the defining figure is certainly Descartes, whose convictions about the value of a mechanical model had a powerful impact on the medical profession:

Because it is the experience of everyone from childhood that many of our movements obey the will...this has disposed us to believe that the soul is the principle behind all of them. And the ignorance of anatomy and mechanics has contributed to this, for in considering only the exterior of the human body, we never imagined 
that it had enough organs or springs in it to move itself in all the different ways in which we see it move (Descartes 1998, p. 170).

It is certainly accurate to characterize Descartes' mechanistic methodology as reductionistic, and to recognize, as Engel did, the very serious limitations of that approach:

this neglect of the whole inherent in the reductionism of the biomedical model is largely responsible for the physician's preoccupation with the body and disease and corresponding neglect of the patient as a person (Engel 1981, p. 107).

In other passages, however, Engel's writing about reductionism is about ontology rather than methodology. For example, "the biomedical model embraces...reductionism, the philosophic view that complex phenomena are ultimately derived from a single primary principle" (Engel 1977, p. 129). In passages such as this, the issue of reductionism is not a matter of medicine's method; it's a matter of medicine's conceptual foundation, so we're not asking about how medicine should do things. Instead, we're asking about how the world is in itself. Can persons be reduced to bodies? More specifically, is subjective experience the same thing as physical brain states, or do minds (or mental properties) exist in addition to brains (and brain properties)?

When philosophers consider the mind-body question, 'reduction' is automatically understood in this ontological sense, so it's a view that takes a position about how many kinds of things (or properties) exist. Those who think that minds or mental properties reduce to physical items and properties stand opposed to dualism. To be very clear, if you accept reductionism in this sense, you insist that experience is nothing over and above physical brain states. By contrast, those who think that minds (or mental properties) exist at the foundational level are dualists.

It is not always important for medical writers to use the same terms and concepts that philosophers use, but when it comes to the distinction between methodological and ontological reductionism it's actually crucial, because our views on the methodological question readily come apart from our views on the ontological question. We can, for example, reject methodological reductionism as an approach to medicine, while we accept ontological reductionism as a view about the existence of the mental. If we do, we think Engel was right about the problem with medicine's mechanistic focus on the body, but we reject the idea that the mind or mental properties exist. This is a common combination of positions in current writing about holism, a perspective I'll call "reductive holism" that's particularly popular in psychiatry (and one that I will argue is untenable).

More importantly, we can accept methodological reductionism as an approach to medical practice while we reject ontological reductionism, the idea that mental states can be reduced to the physical states of the brain. In fact, Descartes embraced this combination of views:

I knew from this that I was a substance, the whole essence or nature of which was to think and which, in order to exist has no need of any place and does not depend on anything material. Thus this...soul...is completely distinct from the body... and even if the body did not exist the soul would still be everything that it is (Descartes 2000, p. 61). 
While it's accurate to say that Descartes was a reductionist about methodology, it is very seriously inaccurate to say that he was a reductionist about the ontological issue, the question of whether the mind can be reduced to the body. As the quintessential substance dualist, Descartes is very adamantly opposed to ontological reductionism.

This, then, is the first reason why so many of holism's claims about mind and body seem philosophically confused. Because medical writing recognizes Descartes as a methodological reductionist, but then it fails to distinguish methodological from ontological reduction, it slips into describing Descartes as a reductionist about the mind. That is straightforwardly inaccurate.

\subsection{Dualism as "separation of mind and body"}

While the distinction between methodological and ontological reduction is helpful in making sense of holism's philosophically confusing claims, it cannot do the whole job. A far bigger problem lies in holism's definition of dualism, which also fails to recognize philosophers' central concern with the question of the existence of mind (or mental properties).

In the original formulation of the BPSM, Engel defines dualism not ontologically, but epistemically, as "the doctrine that separates the mental from the somatic" (Engel 1977, p. 130). We see this same characterization in Eric Cassell's The Nature of Suffering and the Goals of Medicine (Cassell 1991), another foundational work on holism:

The split between mind and body that has so deeply influenced our approach to medical care was proposed by Descartes to resolve certain philosophical issues. Moreover, Cartesian dualism made it possible for science to escape the control of the church by assigning the noncorporeal, spiritual realm to the church, leaving the physical world as the domain of science (Cassell 1991, p. 32).

This is not inaccurate, philosophically speaking. Descartes did certainly advocate a "split between mind and body", and that split did facilitate the development of medical science. Notice, though, that when we characterize dualism as a matter of separating mind and body in our thinking, we are drawn to the idea that the biomedical model is itself dualistic, a notion that will be straightforwardly inaccurate in a philosophical context. Broadly speaking, the problem with the BMM, as Engel originally characterized it, is that it is monistic. The BMM reduces the mind to the physical material of the body and, for this reason, it overlooks the person.

In Duncan's "Mind-body dualism and the biopsychosocial model of pain: What did Descartes really say?" (Duncan 2000) we can track confusion about dualism in a way that helps us see how it works. Duncan begins by defining dualism as "any concept of mind and body which treats them as distinct entities" (Duncan 2000, p. 485n1) —again, a characterization focused not on whether mind and body both exist, but on how we treat them. He then explains that "Cartesian mental philosophy is seen, often in concert with Newtonian physics, as ushering in an era in which the body is reduced to mechanistic, organic processes, quite separate from the mind" (Duncan 2000, p. 486). 
While the "separation" of mind and body at the end of that sentence is accurate as an account of "Cartesian mental philosophy", for philosophers it's jarring to imagine Descartes' views on mind as facilitating a reductive physicalist model of persons. This tie is then made explicit: "Recent attempts by medical thinkers to overcome organic reductionism in favor of a more holistic representation of disease and health routinely begin by attacking Cartesian dualism" (Duncan 2000, p. 486).

This perplexing claim is entirely in keeping with writing about holism from the 1970s to the present, so it's important to trace the steps that brought us here. Holism begins with the idea that Descartes' methodologically reductive approach to medicine is misguided. Then it defines Cartesian dualism as "separation of mind and body" —and from there it comfortably concludes that reductionism in the BMM was made possible by Cartesian dualism. For philosophers, that conclusion is deeply confused, because Cartesian dualism is not just a matter of separating mind and body in our thinking. It's the view that minds exist as substances, in addition to the physical substances of bodies. For philosophers-including Descartes_Cartesian dualism is directly opposed to reductionism.

When we replace the word 'dualism' with the epistemic notion of "separation of mind and body" (and we're careful to distinguish methodological reduction from ontological reduction), holism's confusing claims become not only sensible, but insightful. Engel wrote:

the biomedical model embraces both reductionism, the philosophic view that complex phenomena are ultimately derived from a single primary principle, and mind-body dualism, the doctrine that separates the mental from the somatic (Engel 1977, p. 130).

Philosophers who read that sentence literally will find it to be incoherent, but Engel does have a point to make in this passage and it's an insight that does define the movement of holism. What he means to say is that "the biomedical model embraces both ontological reductionism, and the separation of mind and body in our medical methodology".

In the end of the day, when we repair Engel's terminological confusions, his view amounts to this: holism rejects Descartes' methodologically reductive approach to medicine but it agrees with Descartes that it's a mistake to reduce the mind to the body. Medicine cannot succeed unless it acknowledges the existence of the mind (or mental properties) as distinct from the body (or physical properties). Once it has accepted the mental, medicine should endeavor to manage the mental and physical features of patients in a way that sees them as unified in the whole person. It remains unclear what position on the existence of mind (or mental properties) holism is reaching for, and I will address that question in Part 4.

\subsection{How terminological confusion has led to deep conceptual confusion}

Medicine's working version of dualism is a facet of philosophy's version. Philosophically speaking, a dualist is someone who holds that mental experiences are distinct from physical brain states in a fundamental account of what exists in the world, so at 
that level we find two kinds of things: minds (or mental properties) and bodies (with physical properties). In medicine, however, a "dualist" is someone who "separates mind and body" in their thinking or medical practice. A dualist in the philosophical sense will indeed "separate mind and body", so as long as we're affirming dualism, medicine's conception doesn't take it too far afield of philosophy's conception.

In the negative, however, problems arise very quickly. When philosophers reject dualism, they insist that only physical items (and properties) exist in a fundamental account of the world. For philosophers, then, rejecting dualism means accepting a fundamental account of human beings and their properties as entirely physical. When holists reject dualism, however, they are chiefly concerned to reject the BMM. For holists, then, rejecting dualism means rejecting a fundamental account of human beings as entirely physical. That disparity is the heart of the problem.

The source of the trouble is this. While it's really not inaccurate to define dualism as "separation of mind and body", when you reject dualism in that form, you're not actually committed to one or the other side of the real dualism debate. You can go either way. You can reject separation as a dualist by insisting that minds (or mental properties) exist but we should think about them as inextricably unified with bodies in whole persons - or you can reject separation as a monist by insisting that minds (or mental properties) aren't actually there at the fundamental level, because only the physical material of the body exists (or the physical properties of the body). Philosophically speaking, these are opposed positions.

For this reason, even after we correct terminological problems with 'reduction' and 'dualism', we find that the banner of holism does continue to fly over contradictory positions. That would be no problem at all if some holists defended a dualistic or nonreductive approach while others defended a reductive approach, but that's rarely what occurs. ${ }^{2}$ Instead, holism is somehow construed as a perspective that can embrace opposing views on ontological reduction.

Along the nonreductive strand we have The Rise and Fall of the Biopsychosocial Model (Ghaemi 2010), where Ghaemi understands holism as it seems Engel intended, and in the way that philosophers tend to do-that is, as a position chiefly defined by rejection of reductive physicalism. Ghaemi suggests that the original BPSM served as the antidote to reductive physicalism in medicine, and that it now serves as the antidote to the biological approach to psychiatry. Woods presents a similar perspective, where holism "requires that the medical gaze toward the person is not one of eliminative reductionism" (Woods 2015, p. 14), and Zucker takes an even stronger position, suggesting that holism is "a strategy... within medicine that stresses... a dualist, interactionist theory of mind and body" (Zucker 1981, p. 159). Similarly, in Humanizing Modern Medicine, Marcum characterizes the BMM as "mechanistic monism", while the remedy to the BMM is consistently framed as "dualism/holism" (Marcum 2008a, p. 19).

Along the reductive strand, by contrast, many researchers, particularly in psychiatry, have seen Engel's literal rejection of "dualism" as holism's defining feature. These researchers insist that holism's central goal has always been to do away with "the

\footnotetext{
2 There are notable exceptions in Gabbard (2000) and Henningsen (2015), though without the terminology philosophers prefer.
} 
mind-brain dichotomy", and from this perspective holism is conceptually aligned with a biological foundation for psychiatry. In "The persistence of mind-brain dualism in psychiatric reasoning about clinical scenarios", for example, Miresco and Kirmayer (2006) begin with this:

Mind-brain dualism is the idea that the mind is somehow distinct from the brain and that its essence cannot be reduced to purely material and deterministic neurological mechanisms... Although many continue to support the view that mental phenomena result from emergent levels of organization of the brain, the idea that mind and brain are different entities is no longer credible in medical science. Indeed, the last few decades have seen efforts to develop integrative models heralded by claims that dualism in psychiatry has finally been overcome (Miresco and Kirmayer 2006, p. 913). ${ }^{3}$

While it's great to see a philosophically accurate definition of dualism here (at least property dualism in the broadest sense), these authors seem to be sure that reductive physicalism has firmly been established as the only credible position in medicine and psychiatry. Unfortunately, to support that assumption they primarily cite Engel, suggesting that his "integrative" BPSM is the primary tool medicine has used to advance the reductionistic program.

In another study along these lines, "Dualism persists in the science of the mind" (Demertzi et al. 2009), researchers similarly assume that the BPSM is grounded in reductive physicalism. What the study aims chiefly to show is that in spite of the diligent efforts of holists and advocates of the BPSM, healthcare professionals and the lay public continue to be dualists. The study supports this conclusion by examining responses to a series of claims - centrally that "mind and body are two separate things" and that "the mind is fundamentally physical" (Demertzi et al. 2009, p. 2) - then noting that a great many people accept the former and reject the latter. What's most important here is that, like Miresco and Kirmayer, these authors never see a need to argue that reductive physicalism is the best way to understand or improve holism. Instead, they assume from the start that holism and the BPSM are naturally, and indeed universally, understood to be based on a reductionistic perspective.

Ghaemi is correct to point out that advocates of the BPSM stand firmly on the non-reductive, non-biological side in the context of debate about pharmaceutical versus psychotherapeutic approaches to mental illness, as Engel did. It's important to recognize, though, that it's also common for advocates of the BPSM to assume that mind (or mental properties) should be "reduced to purely material and deterministic neurological mechanisms" (Miresco and Kirmayer 2006) — not as if that would be a novel new way of doing things, but as if Engel's own holism has always been understood in these terms. For philosophers unfamiliar with medical writing, this conceptual confusion may seem impossibly far-fetched, but it's difficult for any field to reimagine its foundations once they've become entrenched.

\footnotetext{
${ }^{3}$ Miresco and Kirmayer actually conflate two distinct philosophical positions in this paper, suggesting that emergence is a form of reductive physicalism. This kind of confusion is generally unchallenged in writing about holism in psychiatry.
} 


\section{Part 3: Reductive holism and its threat to public health}

Where the philosopher finishes, there begins the physician. Aristotle

\subsection{Conceptual problems with reductive holism}

As I've presented the core problem, holism sets out with an incoherent philosophical goal - to "do away with the reductionism and mind-body dualism inherent in the biomedical model" (Easton 1982, p. 1185). As I've diagnosed it, the problem arises from inaccurate definitions of basic philosophical terms. If by 'reductionism' we mean methodological reductionism, and by 'dualism' we mean separation of mind and body in our thinking or medical practice, then it will make sense to insist that Descartes' dualistic reductionism is responsible for the ills of the biomedical model. But this is not what 'dualism' and 'reductionism' mean for philosophers in the context of the mind-body problem, so for philosophers that claim - and all the claims that derive from it-are incoherent.

When we understand the philosophical meaning of these terms correctly, we see that dualism and reductionism are opposing positions. It is not possible for the BMM to be grounded in dualistic reductionism, so it is not possible for holism to offer a remedy for that combination. What, then, are holists actually aiming to do? I have argued that as a result of terminological confusions, understanding of holism's goal is conceptually divided. Nonreductive holists see its chief aim as rejection of reductionism, while reductive holists see its chief aim as rejection of dualism-not actual dualism, but dualism mistakenly defined as the separation of mind and body in our thinking, language and medical practice.

When we correct the terminological confusions, nonreductive holism emerges as internally consistent and philosophically viable. As Engel saw it, the primary problem with the BMM is that it reduces experiences to biology, and this is why it addresses patients as bodies rather than persons. Nonreductive holism fixes that problem by insisting that medical science must broaden its scope to include the realm of experience. When it does that well, clinicians see patients as whole persons in whom biological, psychological and social elements are inextricably unified. There is still work to do in pinning down the specific position on mind that nonreductive holism demands or implies, and I'll address that question in Part 4. Whatever its views on mind turn out to be, there is nothing about the general picture of nonreductive holism that's conceptually problematic.

Reductive holism, on the other hand, has severe conceptual problems. Most obviously, the term 'reductive holism' is an oxymoron. Holism of any kind proposes that many disparate elements are present and unified. Reductionism of any kind proposes, by contrast, that while it might seem that we have many disparate elements, in reality all of them can be reduced to one element. For a reductionist we do not have multiple things or ideas that we can set out to conceptualize as "whole".

When we think about the foundations for medicine, this is more than just a word game. Reductive holists insist that "the mind is indivisible from the brain" (White et al. 2012) because mind can be "reduced to purely material and deterministic neurological 
mechanisms" (Miresco and Kirmayer 2006). While it might well be possible to defend reductionism as the right approach for medicine and psychiatry, it is very difficult to see how that approach could align with holism. This is the heart of the problem, conceptually speaking. Reductive holists routinely cite Engel and the BPSM as the foundation for the reductionist program - not as a new and philosophically complex innovation, but as if Engel's own holism has always been understood to be reductive. That is simply not accurate.

The trouble for reductive holists, then, is not reductionism per se, but the combination of reductionism with holism. It is a mistake to suggest that holism and the BPSM have always been understood as reductionistic, and it is difficult to see how reductionism and holism can be combined even if we do recognize the effort as an innovation.

Finally and most simply, even if we managed to develop some fancy philosophical footwork that makes it possible to align reductionism with holism, that project would directly oppose holism's historical purpose. However we conceive of it, holism has to be an antidote to the biomedical model, a corrective for the mistaken idea that patients are bodies rather than persons with experiences. We might feel strongly that reductionism is the right way to go in medicine-but if we do then we favor the BMM, not the antidote of holism. In this sense too, reductive holism is a conceptual contortion that cannot be put right.

Medicine, however, is not philosophy, and it is not a theoretical science. Medical science does not play out in the conceptual realm, that is to say. It plays out in practice. If we want to understand the viability of reductive holism versus nonreductive holism it is not enough to consider the conceptual merits and challenges of each approach. The real test lies at the level of practice. What does reductive holism look like in everyday clinical medicine, and how does that picture differ from practice that embraces nonreductive holism?

Deep conceptual confusion rarely leads to viable empirical results. I will suggest that this truism holds in medicine as it does in other sciences. The conceptual incoherence of "reductive holism" is manifested in clinical practices that are threatening to patient health.

\subsection{The path from reductive holism to deliberate diagnostic vagueness}

The central innovation that holism introduces at the practical level is to broaden the scope of clinical practice beyond biology so that mind is welcomed into the exam room. No matter what picture of holism we might prefer, that is to say, holists will all agree that psychological explanations for symptoms should be drawn into the professional framework as medically legitimate, and medically relevant. For this reason, just as holism invigorated the profession of bioethics, it also facilitated the development of psychosomatic medicine as a profession whose research has relevance for doctors in everyday practice. In this sense, though psychosomatic medicine is actually a subdiscipline of psychiatry, Engel often presented it as a paradigm for the sort of "integrated mind-body medicine" that holism aims for (Engel 1967). Unfortunately, 
because holism is conceptually splintered into nonreductive and reductive strands, it offers two very different approaches to the mind-body diagnostic line.

If we stick with the nonreductive strand of holism that Engel recommends, when we bring the mind into the exam room we must continue to recognize it as mind rather than reducing it to the biology of the body. As a result, though we accept that bodily health is inextricably interwoven with psychosocial well-being, we insist that at the level of medical practice psychiatric conditions must be clearly distinguished from biomedical conditions. When doctors construe psychiatric problems as biological problems, that is to say, they overlook the person in favor of the body, reverting to the BMM. This will be very important in Part 4, when we try to sort out the specific nonreductive view on mind that holism demands. At the level of actual medical care, when clinicians see all of patients' maladies as biological diseases, they straightforwardly fail to practice in the way that is recommended by nonreductive holism.

If we accept the reductive strand of holism, however, our picture of the clinical mind-body line will look radically different. This approach is laid out directly in "Time to end the distinction between mental and neurological illnesses". Like Miresco and Kirmayer, author P.D. White and colleagues begin with a reductive programme, where mind can "be reduced to purely material and deterministic neurological mechanisms" (Miresco and Kirmayer 2006, p. 913). Citing a long series of neuroscientific studies on mental health disorders, White and colleagues suggest that neuroscience has now definitively established that "the mind is indivisible from the brain" (White et al. 2012, p. 1). Based on that emphatic rejection of dualism-not as it is in philosophy, but as Engel misdefined it - they conclude that we must "end the distinction between mental and neurological illnesses" (White et al. 2012, p. 1).

Because the reductive strand of holism embraces Engel's confused definition of dualism, it leads researchers to recommend rejection of separation in very literal terms at the level of practice. So it's not just that we refuse to separate mind and body in our conceptual cogitations. It's that we refuse to separate them in actual diagnostic practice. Holism in its reductive form is routinely understood to imply that the boundaries between medical and mental health conditions are intrinsically vague — an idea I will refer to as the "vagueness thesis".

It's important to note that in itself the reductive picture, and the vagueness thesis that grows out of it, are perfectly coherent. As reductionists we reduce the mental to the physical, then we reject the idea that mind and body are separate, not only conceptually but also diagnostically. The trouble arises when we combine that picture with holism-when White and colleagues insist, as if it's perfectly obvious, that the reductionist programme they propose will "promote a biopsychosocial model". First, as a matter of factual accuracy, Engel's BPSM definitively rejects reductionism. Second, even if we do recognize that reductive holism would be a radical innovation to the BPSM, it's hard to see how we can actually make the combination work. Third, we can now see the most serious challenge that project would involve: nonreductive holism demands a continual distinction in practice between problems caused by psychology and problems caused by biology. When doctors reject that distinction, addressing every malady as a biological disease, they are not practicing holism. They are practicing the biomedical model. 
Philosophers might be inclined to assume that it's rare for those in the medical professions to attempt the conceptual backbends required by reductive holism. That is not the case. Though nonreductive holism clearly rejects the idea that psychiatric disorders should be addressed as biological diseases, the vagueness thesis has become everyday dogma in the medical professions, particularly in psychiatry and bioethics. In spite of serious conceptual problems at the origins of the thesis, that is to say, it is common practice to equate holism with the idea that medical and mental health conditions are not distinct. We see this clearly in the explanatory introduction to the DSM-IV in 1994:

The term mental disorder unfortunately implies a distinction between 'mental' disorders and 'physical' disorders that is an... anachronism.... The term persists in the title of DSM- IV because we have not found an appropriate substitute (APA 1994, p. xxx).

We see it again in more explicit form in discussion of the terms 'mental disorders' and 'psychiatric disorders' during the development of DSM-5:

"Mental" implies a Cartesian view of the mind-body problem.... The term "psychiatric disorder' may be preferable insofar as it emphasizes that these conditions are not purely 'mental', and that the line between 'psychiatric disorder' and 'other medical disorders' is not a sharp one (Stein et al. 2010, p. 1760).

The vagueness thesis marks the juncture where armchair philosophy on the mindbody problem is transformed into action that directly affects the health of living human persons, particularly those with bodily symptoms that remain undiagnosed.

\subsection{Deliberate diagnostic vagueness in the mind-body borderlands}

Undiagnosed or unexplained symptoms are very common in everyday medicine. While research on prevalence has led to widely varied results, textbooks and guidelines commonly settle in a middle range, where roughly half of outpatients seeking medical care get a medical diagnosis, while half have symptoms that are unexplained (O'Leary 2018a). According to these guidelines, patients with unexplained symptoms are as common as all patients with medical diagnosis combined (Greenberg 2017; Joint Commissioning Panel for Mental Health 2017).

Every case of unexplained symptoms could be caused by an unrecognized biomedical condition. As long as we're holists it will also be possible that unexplained symptoms are actually "not attributable to verifiable, conventionally defined diseases" (Fink and Schroder 2010, p. 415) because they're caused by "psychological conflict" that is "transformed or transduced into bodily distress" (Kirmayer and Young 1998, p. 420). There are a great many terms in use to describe symptoms of this kind, and for our purposes "psychosomatic symptoms" will be the clearest and most neutral option. $^{4}$

\footnotetext{
4 As I am using the term in this paper, 'psychosomatic symptoms' does not include symptoms of biomedical conditions originally caused or triggered by psychological distress, such as anxiety-induced asthma attacks or stress-related high blood pressure.
} 
Psychosomatic symptoms sit right at the mind-body divide in medicine. If we want to see what clinicians actually do in relation to mind and body, this will be the place to look, and if we want to understand what philosophical picture of mind underlies medical practice, we will see it best if we investigate standards for diagnosis at this line. In this sense, patients with unexplained symptoms are uniquely gathered in the mind-body borderlands. They are those whose symptoms could be either biomedical or psychological, that is, they are patients who could require either medical or psychiatric care. How should doctors handle this very common form of the mind-body divide in everyday practice?

If we accept Engel's nonreductive approach, we will continue to insist on practice that distinguishes between biological and psychological disorders-so when a doctor is unsure which kind of problem she's dealing with, she should set out to resolve that question with all the caution and clarity that typically define diagnostic practice. When we start from the reductive strand of holism, however, the vagueness thesis will direct the doctor not to double down on her diagnostic efforts in cases of uncertainty, but to abandon them. There is no clear line between medical and mental health conditions, the thesis literally tells her, so in every case where a doctor sets out to draw a crisp diagnostic distinction between disease and psychological distress, she is acting on philosophical misunderstanding.

The field of psychosomatic medicine is unequivocally grounded in the reductive strand of holism, and it is the field of psychosomatic medicine that develops guidelines for managing the large portion of medical cases where symptoms remain unexplained (O'Leary 2018b). This is Schwab describing the goals of the field back in 1984:

In full accord with the established principles of psychosomatic medicine, there is a lessening of the tendency to view the patient dichotomously as being "organic or functional." Instead, collaborative work by internists and psychiatrists enables each specialist to conceptualize the patient as a total person, a psychobiologic unit. (Schwab 1985, p. 584).

Psychosomatic medicine continues to characterize itself in this way, most recently working to revise the term "medically unexplained symptoms", because it "reflects dualistic thinking-regarding symptoms as either 'organic' or 'non organic/psychological" (Creed et al. 2010, p. 5). In this sense, both originally and in our time, psychosomatic medicine has been defined by a commitment to diagnostic vagueness at the mind-body line, by "the necessity of not trying to force these disorders into either a 'mental' or 'physical' classification" (Creed et al. 2010, p. 5).

As an approach to diagnostic uncertainty, the vagueness thesis has had a profound impact on patient care, or at least on the principles that direct doctors' response to unexplained symptoms in medical education. Based on the directive to avoid diagnostic distinctions at the line between psychiatry and medicine, research in this area routinely proceeds as if all patients with unexplained symptoms should be understood to suffer from psycho-somatic conditions (O'Leary 2018a). That assumption is now so commonplace that the research summary system known as "UpToDate" asserts in its chapter on psychiatry: "More than $50 \%$ of patients presenting to outpatient medical clinics with a physical complaint do not have a medical condition" (Greenberg 2017). In the UK's National Health Service that astonishing idea has been put into practice 
with a program that directs all patients with unexplained physical symptoms onto a track where their care will be focused on mental health support (NHS 2018).

\subsection{Evidence that the vagueness thesis interferes with safe patient care}

Outside the conceptual framework of psychosomatic medicine, the problem with deliberate diagnostic vagueness seems immediately evident. No matter what metaphysical account we prefer to understand mind and body, it will still be the case that diagnostic error is possible at the boundary between psychiatry and medicine. More than that, no matter what metaphysical account we prefer, it will still be dangerous to provide only psychiatric care to patients in need of medical care.

Imagine a patient who suffers from undiagnosed early-stage lung cancer, someone who begins as one of the great many patients with unexplained symptoms. Insofar as her doctor chooses to follow the directives of UpToDate and the UK's National Health Service, she will understand this patient as someone for whom continued diagnostic effort would be misguided, someone with a mind-body interface disorder best managed with mental health support-but of course a patient with early-stage lung cancer who receives only psychiatric care will not survive. The British press covered a story of this kind not long ago (Philipson 2013), where an assistant professor in international relations suffered for years from unexplained symptoms construed as psychosomatic. "How is it possible", she asked in a public blog just before her death, "that a 36-year-old, health...conscious, occasionally social smoking, middle class, fiancé of a doctor can develop metastatic lung cancer unnoticed. How?!?" (Smirl 2012).

If we accept the vagueness thesis as a principle for practice, we understand undiagnosed symptoms to be caused by a condition that can't be rightly classified in psychiatry or in medicine, so we take it to be impossible to make a diagnostic error at the mind-body line (Sharpe and Bass 2003; Edwards 2019). Outside of psychosomatic medicine, however, we find evidence that error of this kind is problematic for public health (Butler and Zeman 2005; Koyama et al. 2018). For example, more than half of patients surveyed with autoimmune disease report that they've been wrongly denied the medical care they needed at some time on the basis of mistaken psychosomatic diagnosis (AARDA 2014). Similarly, studies show strong ties between mistaken psychosomatic diagnosis and delay in accurate diagnosis and treatment of rare disease (Kole and Faurisson 2009). Based on conservative prevalence estimates (NIH 2012; Global Genes Project 2013), if we assume only half of rare disease patients are affected by this problem, we find 12 million Americans in these two groups alone have suffered without the care they need as a result of diagnostic error at the line between psychiatry and medicine.

The most decisive evidence we have for the seriousness of this problem is "chronic fatigue syndrome", known in research as myalgic encephalomyelitis/chronic fatigue syndrome (ME/CFS). Because a clear biological explanation for this condition has long been elusive, and psychiatry strongly advocates the vagueness thesis as a diagnostic practice, ME/CFS has long been construed as a paradigm of psycho-somatic illness. While that approach has guided ME/CFS care across the globe for decades, in 2015 
the Institute of Medicine insisted that it has been a mistake (IOM 2015). Biological research, they concluded, has now shown that ME/CFS is a serious biomedical disease along the lines of diabetes or heart disease (Komaroff 2019). This conclusion has now been accepted by the NIH (Green et al. 2015), the Agency for Healthcare Research and Quality (2014), and the Centers for Disease Control (2018) who have implemented the change in research orientation and practice guidelines. Recently the UK government awarded substantial funding for DNA research on ME/CFS - that is, for ME/CFS defined as a biological disease.

Even if we agree with psychiatrists who still insist that ME/CFS is a psycho-somatic disorder (Sharpe and Greco 2019), dissolution of professional consensus on that point will still force us to question the safety of the vagueness thesis as a principle for practice. Regardless of whether we construe ME/CFS as a biomedical disease or a psychiatric condition, the existence of the debate does establish that it's possible to make a diagnostic mistake at the line between psychiatry and medicine, and that doing so can be harmful for patients in need on a very large scale (O'Leary 2020a).

It is important to note that this issue has suddenly become pressing (Raskin et al. 2020; Harding 2020; Vastag and Mazur 2020; Lowenstein 2020; Yong 2020). A substantial portion of patients who've suffered from acute Covid-19 are reporting ongoing fatigue in the form that's typical of ME/CFS (Open Medicine Foundation 2020; Covid19 Recovery Awareness 2020; Assaf et al. 2020), following the pattern of those who've suffered from SARS, MERS, Epstein-Barr and other viruses. While many biological researchers have coordinated efforts to address this problem (Open Medicine Foundation 2020), many in psychiatry have relied on the vagueness thesis, proposing that post-Covid fatigue must a mind-body disorder best managed by psychiatry (Holmes et al. 2020; University College London 2020; Gill 2020; Chalder and McCormack 2020). It will not be possible to determine the best course of care for this increasingly large and vocal patient group unless we're clear about the reasoning that supports the vagueness thesis as a principle for practice. More specifically, we will need to be very clear about how philosophical confusion can undermine standards for safe, cautious patient care in the context of diagnostic uncertainty.

\section{Part 4: Is naturalistic dualism the metaphysical ground for holism?}

Eventually it will become intolerable to have a theory of medicine that cannot accommodate the evidence for the effect on health of the meaning of experience, expectations, beliefs, intentionality, and relationships (McWhinney 2002, p. x).

\subsection{Basic facts about philosophy, reductionism and dualism}

Driven by Engel's holistic concerns, medicine has embraced a distinctly philosophical identity in the last 40 years. Medical professionals and patients alike now see a new and improved version of the profession that rejects the traditional model's wholly physical account of patients-but the conceptual meaning of that idea remains terribly confused. 
It is long past time that we set out to clarify the metaphysical foundation for holism in a way that aligns with current understanding in philosophy.

Before we dig into that task, it's important to articulate a few straightforward corrections to discourse about holism that comments on philosophy. First, though research in psychiatry often suggests otherwise, philosophy in our time is not a prima facie justification for reductionism. As Kim succinctly put it back in 1989, "reductionism in the mind-body problem has been out of fashion for two decades" (Kim 1989, p. 32).

Second, contrary to conceptual discussions in DSM-IV and DSM-5, philosophy does not provide a prima facie justification for the vagueness thesis, the idea that boundaries between psychiatric and medical disorders must be intrinsically vague. As we saw in Part 3, the vagueness thesis arises from reductive holism's effort to "eliminate the mind-brain dichotomy" in our thinking, language and practice. Effort of that kind is generally not defended in philosophy of mind. In fact, as Davies and Roache describe things in "Reassessing biopsychosocial psychiatry", current orthodoxy in philosophy proposes that "descriptions and explanations expressed in the language of psychology are irreducible to descriptions and explanations expressed in the language of biology" (Davies and Roache 2017, p. 4). While it is certainly possible to defend the vagueness thesis on philosophical grounds, it is inaccurate to suggest that contemporary philosophers are generally united behind that kind of effort.

Reductive holism is, first, a conceptually incoherent combination of ideas, or at least it is immensely problematic. Second, we've seen evidence that, through literal application of the vagueness thesis in clinical recommendations, reductive holism has led to problems in practice, particularly with the large portion of patients whose symptoms might have either psychological or biological explanations. We see now that, third, while reductive holists often imply that philosophy demands such a combination of ideas, that is actually not the case. For all three reasons it seems clear that reductive holism is a nonstarter. If we want to find a way to make sense of mind in medicine as holists, we must begin with nonreductionism.

The real challenge in pinning down holism's metaphysical foundation is in sorting out the nonreductive position on mind that it requires. What's made this confoundingly difficult is holism's persistent, deeply confused insistence on doing away with "the reductionism and mind-body dualism inherent in the biomedical model" (Easton 1982). Because there is no coherent position that accepts both reductionism and Cartesian dualism, there is no coherent position that can be characterized as an antidote to it. Medicine's metaphysical morass results from decades of effort to grapple with this impossible challenge.

The fact is that we can make sense of the BMM either as a reductive approach, where mental states dissolve into states of the body, or as an approach based on Cartesian dualism, where the difference between mental states and bodily states is explained by the existence of separate mental and physical substances within each person. These are not the same foundation.

In fact, though either will work as a metaphysical ground for the body-focused approach of the BMM, they are diametrically opposed. In this passage, Engel comes close to conceptual clarity about the opposing options, and if he had just taken a few more steps in this direction, medicine might well have avoided its current confusions: 
Biomedical dogma requires that all disease, including "mental" disease, be conceptualized in terms of derangement of underlying physical mechanisms. This permits only two alternatives whereby behavior and disease can be reconciled: the reductionist, which says that all behavioral phenomena of disease must be conceptualized in terms of physicochemical principles; and the exclusionist, which says that whatever is not capable of being so explained must be excluded from the category of disease (Engel 1977, p. 380).

What holism really wants to do is to find a way of understanding mental states where we avoid the two poles of denying mind and accepting mind in a way that sets it outside the scope of medical science. Philosophically speaking, that is to say, when holism rejects a purely biological model for medicine it seeks to (1) reject reductionism, while it also (2) rejects Cartesian substance dualism. Research on holism in the last 10 years has become increasingly clear on this point, and increasingly vocal about the importance of finally pinning down that middle way:

Does...the notion of mental disorder lead to a dilemma that consists in either implying a Cartesian account of the mind-body relation or in the need to give up a notion of mental disorder in its own right? Many psychiatrists seem to believe that denying substance dualism requires a purely neurophysiological stance for explaining mental disorder. However, this conviction is based on a limited awareness of the philosophical debate on the mind-body problem (Schramme 2013, p. 1).

According to Schramme, when we pursue the middle way, "mental illness is not reducible to brain illness, even when mental phenomena have their basis in the brain" (Schramme 2013, p. 8). Gabbard (2000) and Jungert (2013) have also argued for this kind of approach, as has Natalie Banner (2013), who states directly, "one can legitimately hold both that ultimately, the mind is made up of brain stuff, and that mental disorders are not reducible to brain disorders" (Banner 2013, p. 510).

Philosophy does offer these kinds of alternatives. In fact, intensive effort in the last five decades has highlighted the space between the poles of reductionism and Cartesian dualism and populated it with a range of subtler options (Putnam 1967; Davidson 1979; Fodor 1974; Block 1980; McLaughlin 1991; Chalmers 1996; Kim $1996,1998,2005)$. If we want to clarify medicine's position in this realm, however, we must begin with accurate and consistent use of the term 'dualism'.

To be very clear, dualism is not the epistemic idea that we should "separate mind and body" in our thinking, language or practice. Dualism is an ontological position, a view about how many kinds of entities or properties exist in a fundamental account of the world. Moreover, though it's clear that holists must indeed reject the ontological position of Cartesian substance dualism, it is not at all clear that they should reject dualism generally. As Susan Schneider has put it, "contemporary philosophy of mind sees the question of the nature of substance as being settled in favor of the physicalist. Dualism about properties, in contrast, is regarded as being a live option" (Schneider 2012, p. 51). 


\subsection{Naturalistic dualism and biological psychiatry}

Philosophy offers two central alternatives in the territory between reductionism and substance dualism: "nonreductive physicalism" and "naturalistic dualism". Confusing as the terminology may be, both embrace physicalism about substances, so both align against the Cartesian dualist's view that persons are split into mental and physical substances. In addition, both are nonreductive positions, so both align against reductionism just as Engel does. What makes it possible to combine rejection of Cartesian dualism with rejection of reductionism is the idea that some physical brain states have mental properties. For nonreductive physicalists and naturalistic dualists alike, "mental properties are real, and not just heuristic devices for making convenient predictions" (Kallestrup 2006, p. 468).

The point of debate between nonreductive physicalists and naturalistic dualists is a matter of how far we're willing to go with the existence of mental properties. For the nonreductive physicalist, mental properties do genuinely arise in the world. They "supervene on" or "emerge from" physical properties. When we count the things that exist in the end of the day, however, mental properties are ultimately identified as physical properties. For the naturalistic dualist, by contrast, the difference between mental and physical properties does not disappear at the fundamental level. When we count the things that exist, we find that while all substances are physical, and most of their properties are physical, some properties exist that are mental in the end of the day.

The difference between these two perspectives is immensely important for medicine because medicine is a science. For the nonreductive physicalist all sciences can proceed with business as usual, because while mental properties will sometimes supervene on or emerge from physical properties, mental properties will still be fundamentally physical in the end of the day. For the naturalistic dualist, on the other hand, science needs to respond to the fundamental reality of the mental. As David Chalmers puts it, "the fact that consciousness accompanies a given physical process is an additional fact, it is not explainable by telling the physical facts" (Chalmers 1996, p. 107).

Which approach should medicine choose? Generally speaking, given Engel's confusion about what dualism amounts to, and his bizarre insistence that dualism and reductionism are one and the same view, many now assume that holism is opposed to dualism in all its forms. Bioethics has taken a particularly strong stance in this way - so much so that rejection of dualism seems to carry the force of an ethical imperative. In 2007, however, Rachel Cooper explored dualism in the context of psychiatry, pointing out that "within the psychiatric literature dualism is sometimes presented as being a dead theory. But is not". She concludes,

...[naturalistic] dualism is compatible with all neuroscientific findings, and with the fact that psychoactive medications can change mental states. One can thus adopt dualism without this causing any problems for psychiatric research (Cooper 2007, p. 106).

In 2018, Hane Maung followed up on Cooper's conclusion with a substantial defense for naturalistic dualism as a "a way of maintaining the irreducibility of subjective experience while accepting the scientific claims of biological psychiatry" (Maung 
2019, p. 68). In "Dualism and its place in a philosophical structure for psychiatry" (Maung 2019), Maung presents the tenets of naturalistic dualism as defended by Chalmers in a way that finally does refute knee-jerk resistance to dualism in psychiatry.

First, he clarifies, Chalmers does not propose that all mental states or properties must exist at the fundamental level. Instead, he distinguishes psychological and phenomenal concepts of the mental, arguing that while cognitive science can explain psychological states and properties, no account of that kind will be adequate to explain phenomenal states-that is, states of experience. Maung characterizes the difference in this way:

The phenomenal concept of the mental is that which concerns the subjective quality of experience. When one is involved in perceiving, thinking, and acting, there occur various complex causal processes in one's brain. However, these processes do not usually go on "in the dark", but are associated with a phenomenal feel (Chalmers 1996, p. 4). They are accompanied by a first-person subject of experience, that is to say, by consciousness. To borrow a phrase from Thomas Nagel (1974), there is usually "something it is like" to be in a given mental state.

For this reason, naturalistic dualism is not dualism about mental and physical properties generally. It is dualism specifically about experiential properties as distinct from physical properties. Moreover, because Chalmers insists that there are psychophysical laws that tie experiential properties to physical properties, naturalistic dualism demands a rethinking of our scientific sensibilities. If we accept naturalistic dualism we accept that science has some work to do in explaining how we get from physical facts to experiential facts.

Second, naturalistic dualism is motivated by "the perceived failure of physicalism to account for the subjective experience of consciousness" (Maung 2019, p. 63). Chalmers asks,

How can we explain why there is something it is like to entertain a mental image, or to experience an emotion? It is widely agreed that experience arises from a physical basis, but we have no good explanation of why and how it so arises. Why should physical processing give rise to a rich inner life at all? It seems objectively unreasonable that it should, and yet it does (Chalmers 1996, p. 3).

If naturalistic dualism is compatible with biological psychiatry—and it's hard to refute Cooper and Maung on this point- then it will be compatible with holism. More than that, while Engel does generally work with the language of the "psychological" in contrast with the "biological" and the "social", holism's concern with the psychological is specifically focused on experience. For this reason, naturalistic dualism seems to capture the spirit of holism better than nonreductive physicalism.

\subsection{Naturalistic dualism versus nonreductive physicalism for holism's goals}

Roughly speaking, until the 1970s medicine understood itself straightforwardly as a physical science, one that "assumes disease to be fully accounted for by deviations from the norm of measurable biological (somatic) variables" (Engel 1977, p. 130). At 
that point the profession found itself in a sort of double crisis. In the realm of ethics, humanism demanded recognition of patients as persons and not merely bodies, and on that basis it clarified the core ideas of clinical ethics as we now understand them. At the same time - and as a distinct kind of movement-holism proposed that humanism's ethical demands must be grounded in a change in medicine's understanding of itself as a science. If we want to succeed in the goal of improving and protecting health, Engel insisted, we must broaden the scope of medical science to include experience. As Borrell-Carrio and colleagues have described it...

Engel did not deny that the mainstream of biomedical research had fostered important advances in medicine, but he criticized its excessively narrow focus for leading clinicians to...[ignore] the possibility that the subjective experience of the patient was amenable to scientific study (Borrell-Carrio et al. 2004, p. 576).

When we consider options for holism's metaphysical foundation, then, we must seek an approach that will not only (1) reject reductionism and (2) reject Cartesian substance dualism, but also one that will (3) demand that we revise our understanding of medical science to include experience. In this way, holism seems to have a natural home in naturalistic dualism. If medicine had overtly adopted the picture of naturalistic dualism in the late twentieth century, that conceptual change would certainly have forced a sharp turn away from the BMM in the direction of holism. More than that, naturalistic dualism can make sense of 40 years of subsequent effort to understand and implement a new approach to medical science that makes room for mind.

If we adopt the nonreductive physicalist approach of supervenience we can successfully explain the metaphysical ideas we end up with in holism, and that would be a substantial improvement on the confused status quo. When it comes to medicine's history, though, and the force with which holism has demanded a change to medical science, it seems that supervenience falls short. If experiences do disappear in a fundamental scientific account, why should we see the BMM as deeply and irretrievably mistaken? On this issue, Kim's comments in "The myth of nonreductive materialism" are surprisingly apt: "Given all this, it's difficult to see what point there is in recognizing mentality as a feature of the world.... It allows mentality to exist, but this doesn't strike me as a form of existence worth having" (Kim 1989, p. 32).

Emergence is a different approach to nonreductive physicalism, and it argues for a deeper metaphysical distinction between experiential properties and physical properties. For this reason, emergence seems like a better candidate than supervenience to motivate and explain decades of effort to turn away from a purely biological model. Both Borrell-Carrio and Marcum have imagined, moreover, that emergence is the metaphysical foundation that holism actually has in mind (Borrell-Carrio et al. 2004; Marcum 2008a). ${ }^{5}$ Chalmers takes a general stand on this issue, however. When emergence does succeed in distinguishing itself from supervenience, he suggests, it continues to "require new fundamental laws" (Chalmers 1996, p. 129) so it collapses into naturalistic dualism. It may be that emergentists can distinguish their position from naturalistic dualism in a way that would still force a strong turn away from the

\footnotetext{
5 Note that while Marcum does offer a compelling discussion of emergence as the foundation for holism, he also consistently equates holism with dualism (Marcum 2008a).
} 
BMM, but until we have an account of that kind, naturalistic dualism will have stronger prima facie plausibility when it comes to (3).

Finally, based on problems that have resulted from the reductive strand of holism in practice, it will not be enough for medicine's metaphysical foundation to (1) reject reductionism, (2) reject Cartesian substance dualism, and (3) demand that we bring experiences into the scope of medical science. It must also (4) bring experiences into medical science in a way that retains their experiential character. If clinicians invite experiences into the exam room but they equate them with bodily properties in the end of the day, it seems we end up in practice with reductive holism-that is, with the conceptual confusions and public health threats that arise from the vagueness thesis. Once again aligning with Kim, it seems the realities of human health force us to get very clear about the difference between nonreductive physicalism and reductionism at the level of medical science.

We know the supervenience physicalist will insist that experiential properties disappear in an accounting of the world at the fundamental level of physics, but we do not know what she has to say about experiential properties in an accounting at the level of medical science. It may be that supervenience can meet Kim's challenge, distinguishing itself from reductionism at the level of physics, and it may be that supervenience can do this in a way that manages to (4) retain the experiential nature of experiential states at the level of medical science. It remains unclear how supervenience could accomplish this in a way that will also accomplish (3), providing not merely an explanation for holism's current perspective, but a formative demand to reject a purely biological model of medical science.

Though my defense of naturalistic dualism for medicine has been preliminary and provisional, evidence has established now that Engel's general conclusion was right, that medicine is more successful in accomplishing its scientific goals when it considers the complex role that experience plays in human health. Importantly, this is the case even if we continue to evaluate medicine's success in wholly biological terms (e.g. Gouin and Kiecolt-Glaser 2012; Sgambato et al. 2012). While these successes arise from our ability to track the body's responses to the neurological correlates of experience, it is clear that exercise will lose its value if we fail to distinguish experiences from their neurological correlates. The ubiquitous medical catch-phrase, "mindbody integration", is helpful on this score. Incoherent as it is to imagine that we must do something in order to align the mental with the physical, the phrase aligns with Chalmers's expectation that science will ultimately make room for experience as experience.

\section{Part 5: Conclusions}

Medicine is thoroughly permeated with...philosophical questions which can, and do, masquerade as being simply empirical (Gold 1985, p. 664).

Holism is now "woven into the delivery of care at every level" (Greenberg 2017, p. 1). In spite of the distinctly biological focus of evidence-based medicine in our time, the core ideas of holism remain central to medicine, psychiatry, bioethics, psy- 
chosomatic medicine, health policy, health law, health insurance, medical education, and diagnostic coding. Nearly 40 years after Engel originally articulated the BPSM, it continues to ground the foundational claims of the DSM, and WHO's working definition of health. Indeed, holism has become central to cultural understanding of what medicine aims for, to the point where medical marketing makes everyday promises of "integrated mind-body practice" and "whole person care".

In all of these areas, holism's original philosophical confusions routinely lead to incoherence. The WHO, the APA, and the everyday practice of medicine cannot possibly "do away with the reductionism and mind-body dualism inherent in the biomedical model" (Easton 1982) because that goal is incoherent. Holism itself is not incoherent, however. Its usefulness for improving and promoting health has been verified again and again, in theory and in practice, to an extent that Engel likely could not have imagined. So it certainly is important for medicine, and all of its related professions, to aim for a holistic approach. To accomplish that goal, holism's terminological and conceptual confusions must be repaired. As a position that centrally stakes a claim in mind-body territory, holism requires a philosophically stable foundation.

First, dualism has been inaccurately defined as "separation of mind and body". In reality, dualism is the view that we cannot give a wholly physical account of persons and their experiences, and so we must accept the fundamental existence of mind or mental properties.

Second, ethical medical practice does not demand rejection of dualism. This idea runs deep in bioethics, but it is mistaken. Bioethics certainly does not aim to see patients as physical and only physical, and that is what it actually means to reject dualism. On the contrary, bioethics requires a metaphysical picture that will force us to distinguish experiential states from brain states in medical practice. ${ }^{6}$ The only position that maintains this distinction at a fundamental scientific level is naturalistic dualism.

Third, holism is an anti-reductionistic perspective, so it cannot aim to "eliminate the mind-brain dichotomy". Because holism's central insight marks the difference between the body and the person who experiences it, the pervasive strain of holism that sees it as reductive is confused. This point is particularly pressing for psychiatry, and it will be concerning for many, given the common sensibility that rejecting reduction means accepting Cartesian substance dualism. That sensibility is misguided. There are other options, and philosophers in our time have gone to considerable lengths to try to work them out. The fact is that holism's anti-reductionistic stance is well aligned with philosophy in our time, so medical and psychiatric professionals can openly reject reductionism without concern that doing so suggests they're philosophically uninformed.

Fourth, the boundary between medical and psychiatric conditions is not intrinsically vague, or at least that is an idea that currently lacks support. Because the vagueness thesis arises from a reductionistic foundation, it is not supported by holism or by philosophy's general approach to mind and body at this time. Rooting out the vagueness thesis, however, or even tempering enthusiasm for it, is a massive undertak-

\footnotetext{
6 For a detailed discussion of the path from recognition of phenomenal consciousness to medicine's moral character and specific ethical constraints, see my chapter "The Value of Consciousness in Medicine" (O'Leary 2020b), forthcoming in Oxford Studies in Philosophy of Mind.
} 
ing-because giving it up means we must revise the foundational claims of the DSM. We must re-evaluate the areas of bioethics where we rely on the idea that medical illness and mental illness are indistinguishable in the end of the day. We must redefine the field, and the goals, of psychosomatic medicine. Most importantly, we must give up the notion that deliberate diagnostic vagueness is a good idea when patients might suffer from either psychiatric or medical conditions-but there is an immediate payoff on this last endeavor that makes sense of the whole project. For those with autoimmune diseases, rare disorders, and ME/CFS, and for the half of outpatients whose symptoms are undiagnosed, deliberate diagnostic vagueness at the mind-body line has led to substantial suffering and harm, and continues to do so at this time. Medicine, it turns out, is an arena where reductionism can have harmful human consequences.

Finally, corrected holism has implications for philosophy in the armchair. To the extent that holism is the right view (and it's tough to dispute its scientific success), it appears that medical science cannot succeed with a reductive foundation. It appears, moreover, that supervenience physicalism and emergence face challenges in accommodating the changes that holism brings to medical science. I don't claim to have offered a substantial defense of naturalistic dualism as the only viable approach, but I think it's clear that the spirit of holism is captured by naturalistic dualism. We pursue the practice of medicine not because we have bodies, but because we experience them and we dread the day when that will no longer be the case. This is the core revelation that holism carries through the medical professions, and it does make a strong case for dualism.

Acknowledgements This paper was made possible through a fellowship at the Rotman Institute of Philosophy, and through the intellectual creativity of that environment. It is based in part on a presentation at the Rotman Institute-Brain and Mind Institute Joint Coffee Hour in March 2019. I am enormously grateful for discussions on this material with Lisa Feldman Barrett, Michael Anderson, Christopher Viger, Erik Parens, Marie Nicolini, Claire Junga Kim, David Meyers and anonymous reviewers.

\section{References}

Agency for Healthcare Research and Quality. (2014). Diagnosis and treatment of myalgic encephalomyelitis/chronic fatigue syndrome: Systematic review. Resource document. https://effectivehealthcare.ahrq. gov/topics/chronic-fatigue/research. Accessed 17 July 2019.

American Autoimmune-Related Disease Association. (2014). News Briefing 2014: The Status of Autoimmune Disease. Resource document. http://slidegur.com/doc/96420/viewthe-power-pointpresentations. Accessed 17 July 2019.

American Psychiatric Association. (1994). Diagnostic and statistical manual of mental disorders (4th ed.). Washington, DC: American Psychiatric Association.

Arnaudo, E. (2017). Pain and dualism: Which dualism? Journal of Evaluation in Clinical Practice, 23, 1081-1086.

Assaf, G., Davis, H., McCorkell, L., Wei, H., Brooke, O., Akrami, A., Low, R., Mercier, J. \& A. Adetutu. (2020). What Does COVID-19 Recovery Actually Look Like? An Analysis of the Prolonged COVID19 Symptoms Survey by Patient-Led Research Team. Resource document. https://docs.google.com/ document/d/1KmLkOArlJem-PArnBMbSp-S_E3OozD47UzvRG4qM5Yk/edit\#heading=h.16nev7 oixrdw. Accessed 19 June 2020.

Banner, N. F. (2013). Mental disorders are not brain disorders. Journal of Evaluation in Clinical Practice, 19, 509-513.

Block, N. (1980). Introduction: What is functionalism? In N. Block (Ed.), Readings in the philosophy of psychology (Vol. 1, pp. 178-179). Cambridge: Harvard University Press. 
Borrell-Carrio, F., Suchman, A. L., \& Epstein, R. M. (2004). The biopsychosocial model 25 years later: Principles, practice and scientific inquiry. Annals of Family Medicine, 2(6), 576-582.

Butler, C., \& Zeman, A. Z. J. (2005). Neurological syndromes which can be mistaken for psychiatric conditions. Journal of Neurology, Neurosurgery and Psychiatry, 76(Suppl I), i31-i38.

Cassell, E. (1991). The nature of suffering and the goals of medicine (2nd ed.). Oxford: Oxford University Press.

Centers for Disease Control. (2018). Evidence-based treatment guidelines for Myalgic Encephalomyelitis/Chronic Fatigue Syndrome. Solicitation Number: 75D301-18-Q-69445. Resource document. https://www.fbo.gov/index?s=opportunity\&mode=form\&id=30dd6fa6af05215774b9d11d01f9 f6c2\&tab=core\&_cview=0. Accessed 17 July 2019.

Chalder, T., \& McCormack, D. (2020). Persistent (medically unexplained) physical symptoms: A scientist practitioner approach. British Association for Behavioural \& Cognitive Psychotherapies Webcast, June 8. https://www.babcp.com/Conferences/Spring/Webcasts/Persistent-MedicallyUnexplained-Physical-Symptoms-A-Scientist-Practitioner-Approach.aspx. Accessed 19 June 2019.

Chalmers, D. (1996). The conscious mind. In search of a fundamental theory. Oxford: Oxford University Press.

Cooper, R. (2007). Psychiatry and philosophy of science. Stocksfield: Acumen Press.

Covid-19 Recovery Awareness. (2020). Petition: Revise COVID-19 guidelines to accurately reflect recovery periods. Resource document. https:/www.change.org/p/world-health-organization-who-othersrevise-covid-19-guidelines-to-accurately-reflect-recovery-periods. Accessed 19 June 2020.

Creed, F., Guthrie, E., Fink, P., Henningsen, P., Rief, W., Sharpe, M., et al. (2010). Is there a better term than "medically unexplained symptoms"? Journal of Psychosomatic Research, 68(1), 5-8.

Davidson, D. (1979). Mental events. In D. Davidson (Ed.), Essays on actions and events (pp. 207-223). Oxford: Oxford University Press.

Davies, W., \& Roache, R. (2017). Reassessing biopsychosocial psychiatry. British Journal of Psychiatry, 210, 3-5.

Demertzi, A., Liew, C., Ledoux, D., Bruno, M. A., Sharpe, M., \& Zeman, A. (2009). Dualism persists in the science of mind. Annals of the New York Academy of Sciences, 1157, 1-9.

Descartes, R. (1998). Description of the human body. In S. Gaukroger (Ed.), Rene descartes: The world and other writings (pp. 313-324). Cambridge: Cambridge University Press, Cambridge.

Descartes, R. (2000). Discourse on method. In R. Ariew (Trans.), Descartes: Philosophical essays and correspondence (pp. 46-820). Indianappolis: Hackett.

Duncan, G. (2000). Mind-body dualism and the biopsychosocial model of pain: What did Descartes really say?. Journal of Medicine and Philosophy, 25(4), 485-513.

Easton, J. S. (1982). The biopsychosocial approach to the patient. Journal of the American Medical Association, 247(8), 1185-1186.

Edwards, M. (2019). Functional neurological disorder: An ethical turning point for neuroscience. Brain, 142, 1855-1857.

Engel, G. (1967). The concept of psychosomatic disorder. Journal of Psychosomatic Research, 11, 3-9.

Engel, G. (1977). The need for a new medical model. Science, 196(4286), 129-136.

Engel, G. (1981). The clinical application of the biopsychosocial model. Journal of Medicine and Philosophy, 6(2), 101-124.

Fink, P., \& Schroder, P. (2010). One single diagnosis, bodily distress syndrome, succeeded to capture 10 diagnostic categories of functional somatic syndromes and somatoform disorders. Journal of Psychosomatic Research, 68, 415-426.

Fodor, J. (1974). Special sciences (or: The disunity of science as a working hypothesis). Synthese, 28, 97-115.

Gabbard, G. O. (2000). A neurobiologically informed perspective on psychotherapy. British Journal of Psychiatry, 177, 117-122.

Gendle, M. (2016). The problem of dualism in modern western medicine. Mens Sana Monographs, 14(1), 141-151.

Ghaemi, S. N. (2010). The rise and fall of the biopsychosocial model: Reconciling art and science in psychiatry. Baltimore: Johns Hopkins University Press.

Gill, J. (2020). Science Media Center expert comment on treatment and recovery post-COVID infection. Resource document. https://www.sciencemediacentre.org/expert-comment-on-treatment-andrecovery-post-covid-infection/. Accessed 19 June 2020. 
Global Genes Project. (2013). Rare disease impact report. Resource document. https://globalgenes.org/wpcontent/uploads/2013/04/ShireReport-1.pdf. Accessed 17 July 2019.

Gold, J. (1985). Cartesian dualism and the current crisis in medicine: A plea for a philosophical approach. Journal of the Royal Society of Medicine, 78(8), 663-666.

Gouin, J.-P., \& Kiecolt-Glaser, J. K. (2012). The impact of psychological stress on wound healing: Methods and mechanisms. Critical Care Nursing Clinics of North America, 24(2), 201-213.

Green, C. R., Cowan, P., Elk, R., O’Neil, K. M., \& Rasmussen, A. L. (2015). National Institutes of Health Pathways to Prevention Workshop: Advancing the research on myalgic encephalomyelitis/chronic fatigue syndrome. Annals of Internal Medicine, 162(12), 860-865.

Greenberg, D. B. (2017). Somatization. In J. Dimsdale, \& D. Solomon (Eds.), UpToDate. Waltham, MA.

Greenfield, W. (2007). Biopsychosocial model: Helpful or hindering? Psychiatric Times. https://www. psychiatrictimes.com/schizophrenia/biopsychosocial-model-helpful-or-hindering. Accessed 17 July 2019 .

Harding, L. (2020). 'Weird as hell': The Covid-19 patients who have symptoms for months. The Guardian. https://www.theguardian.com/world/2020/may/15/weird-hell-professor-advent-calendarcovid-19-symptoms-paul-garner. Accessed 19 June 2020.

Henningsen, P. (2015). Still modern? Developing the BPSM for the 21 st century. Journal of Psychosomatic Research, 79(5), 362-363.

Holmes, E. A., O’Connor, R. C., Perry, V. H., Tracey, I., Wessely, S., Arseneault, L., et al. (2020). Multidisciplinary research priorities for the COVID-19 pandemic: A call for action for mental health science. Lancet Psychiatry, 7, 547-560.

Howsepian, A. (1977). Reductionism revisited: Return of the biomedical model. In H. Leigh (Ed.), Biopsychosocial approaches in primary care: State of the art challenges for the 21st century (pp. 179-200). New York: Plenwn Press.

Huth, E. (1981). Review: A philosophical basis of medical practice: Toward a philosophy and ethic of the healing professions. Annals of Internal Medicine, 95, 247.

Institute of Medicine. (2015). Beyond myalgic encephalomyelitis/chronic fatigue syndrome: Redefining an illness, report brief. Resource document. http://www.nationalacademies.org/hmd/Reports/2015/MECFS.aspx. Accessed 17 July 2019.

Joint Commissioning Panel for Mental Health. (2017). Guidance for commissioners of services for people with medically unexplained symptoms. Resource document. https://www.jcpmh.info/resource/ guidance-commissioners-services-people-medically-unexplained-symptoms/. Accessed 17 July 2019.

Jungert, M. (2013). Mental realities: The concept of mental disorder and the mind-body problem. Frontiers in Psychology, 4(809), 1-2.

Kallestrup, J. (2006). The causal exclusion argument. Philosophical Studies, 131, 459-485.

Kim, J. (1989). The myth of nonreductive materialism. Proceedings and Addresses of the American Philosophical Association, 63(3), 31-47.

Kim, J. (1996). Philosophy of mind. New York: Westview.

Kim, J. (1998). Mind in a physical world. Cambridge: MIT Press.

Kim, J. (2005). Physicalism, or something near enough. Princeton: Princeton University Press.

Kirmayer, L. J., \& Young, A. (1998). Culture and somatization: Clinical, epidemiological and ethnographic perspectives. Psychosomatic Medicine, 60(4), 420-430.

Kole, A., \& Faurisson, F. (2009). The voice of 12,000 patients: Experiences and expectations of rare disease patients on diagnosis and care in Europe. Resource document. https://www.eurordis.org/publication/ voice-12000-patients. Accessed 17 July 2019.

Komaroff, A. L. (2019). Advances in understanding the pathophysiology of chronic fatigue syndrome. Journal of the American Medical Association, 322(6), 499-500.

Koyama, A., Ohtake, Y., Yasuda, K., Sakai, K., et al. (2018). Avoiding diagnostic errors in psychosomatic medicine: A case series study. Biopsychosocial Medicine, 12(4), 1-8.

Lowenstein, F. (2020). We need to talk about what coronavirus recoveries look like. New York Times. https:// www.nytimes.com/2020/04/13/opinion/coronavirus-recovery.html. Accessed 19 June 2020.

Marcum, J. A. (2008a). Humanizing modern medicine: An introductory philosophy of medicine. New York: Springer.

Marcum, J. A. (2008b). Reflections on humanizing biomedicine. Perspectives in Biological Medicine, 51(3), $392-405$.

Maung, H. (2019). Dualism and its place in a philosophical structure for psychiatry. Medicine, Health Care and Philosophy, 22, 59-69. 
McLaughlin, B. (1991). The rise and fall of British emergentism. In A. Beckermann, et al. (Eds.), Emergence or reduction? Essays on the prospects of nonreductive physicalism (pp. 53-55). New York: de Gruyter.

McWhinney, I. R. (2002). Forward. In L. Foss (Ed.), The end of modern medicine: Biomedical science under a microscope (pp. 9-13). Albany: SUNY press.

Miresco, M. J., \& Kirmayer, L. J. (2006). The persistence of mind-brain dualism in psychiatric reasoning about clinical scenarios. American Journal of Psychiatry, 163(5), 913-918.

National Health Service. (2018). The Improving Access to Psychological Therapies (IAPT) Pathway for People with Long-term Physical Health Conditions and Medically Unexplained Symptoms. Resource document. https://www.england.nhs.uk/wp-content/uploads/2018/03/improving-access-topsychological-therapies-long-term-conditions-pathway.pdf. Accessed 17 July 2019.

National Institutes of Health, National Institute of Environmental Health Sciences. (2012). Autoimmune diseases. Resource document. https://www.niehs.nih.gov/health/materials/autoimmune_diseases_50 8.pdf. Accessed 17 July 2019.

O'Leary, D. (2018a). Why bioethics should be concerned with medically unexplained symptoms. American Journal of Bioethics, 18(5), 6-15.

O'Leary, D. (2018b). Bodily distress syndrome: Concerns about scientific credibility in research and implementation. Journal of Biological Physics and Chemistry, Special Issue on Scientific Integrity, 18, 67-77.

O'Leary, D. (2020a). A concerning display of medical indifference: Reply to 'Chronic fatigue syndrome and an illness-focused approach to care: Controversy, morality and paradox'. Medical Humanities Published Online First: 29 June 2020. https://doi.org/10.1136/medhum-2019-011743.

O'Leary, D. (2020b). The value of consciousness in medicine. In U. Kriegel (Ed.), Oxford studies in philosophy of mind (Vol. 1). Forthcoming.

Open Medicine Foundation. (2020). Study of the possible conversion of COVID-19 patients to ME/CFS. Resource document. https://www.omf.ngo/2020/04/26/tracking-covid-19-patients/. Accessed 19 June 2020.

Paley, J. (2000). Asthma and dualism. Journal of Advanced Nursing, 31(6), 1293-1299.

Pellegrino, E., \& Thomasma, D. C. (1981). A philosophical basic of medical practice: Toward a philosophy and ethic of the healing professions. New York: Oxford University Press.

Philipson, A. (2013). Professor dies of lung cancer after doctors dismiss illness as 'purely psychological'. The Telegraph. https://www.telegraph.co.uk/news/health/news/9917862/Professor-dies-of-lungcancer-after-doctors-dismiss-illness-as-purely-psychological.html. Accessed 17 July 2019.

Putnam, H. (1967). Psychological predicates. In W. H. Capitan \& D. D. Merill (Eds.), Art, mind, and religion (pp. 37-48). Pittsburgh: Pittsburgh University Press.

Raskin, J., Rep. (2020). To amend the Public Health Service Act to authorize and provide for the expansion, intensification, and coordination of the programs and activities of the National Institutes of Health with respect to post-viral chronic neuroimmune diseases, specifically myalgic encephalomyelitis/chronic fatigue syndrome (ME/CFS), to support the COVID-19 response, and other purposes, H.R.7057, 116th Cong.

Rease, J. (2014). The pernicious effect of mind/body dualism in psychiatry. Journal of Psychiatry, 18(1), $1-7$.

Rosenberg, C. (2007). Our present complaint: American medicine, then and now. Baltimore: Johns Hopkins University Press.

Schillmeier, M. (2019). Thinking with the living body: The biopsychosocial model and the cosmopolitics of existence'. Medical Humanities. https://doi.org/10.1136/medhum-2018-011584. Accessed 17 July 2019.

Schneider, S. (2012). Why property dualists must reject substance physicalism. Philosophical Studies, 157(1), 61-76.

Schramme, T. (2013). On the autonomy of the concept of disease in psychiatry. Frontiers in Psychology, 4(457), 1-9.

Schwab, J. J. (1985). Psychosomatic medicine: Its past and present. Psychosomatics, 26(7), 583-585, 588-589, 592-593.

Sgambato, D., Miranda, A., Ranalso, R., Federico, A., \& Romano, M. (2012). The role of stress in inflammatory bowel diseases. Current Pharmaceutical Design, 23(27), 3997-4002.

Sharpe, M., \& Bass, C. (2003). Medically unexplained symptoms in patients attending medical clinics. In D. A. Warrell, T. M. Cox, \& J. D. Firth (Eds.), Oxford textbook of medicine (4th ed., pp. 1296-1302). Oxford: Oxford University Press. 
Sharpe, M., \& Greco, M. (2019). Chronic fatigue syndrome and an illness-focused approach to care: Controversy, morality and paradox. Medical Humanities, 45(2), 183-187.

Smirl, L. (2012). Nice Shoes. Stage V: Stage IV cancer is considered terminal; Stage V is blogging about it. https://lisasmirl.wordpress.com/2012/11/03/nice-shoes/. Accessed 17 July 2019.

Stein, D. J., Phillips, K. A., Bolton, D., Fulford, K. W. M., Sadler, J. Z., \& Kendler, K. S. (2010). What is a mental/psychiatric disorder? From DSM-IV to DSM-V. Psychological Medicine, 40(11), 1759-1765.

Sullivan, M. D. (1986). In what sense is contemporary medicine dualistic? Culture, Medicine and Psychiatry, 10(4), 331-350.

Thomasma, D. C. (2002). Early bioethics. Cambridge Quarterly of Healthcare Ethics, 11, 335-343.

University College London. (2020). Coronavirus infections may lead to delirium and potentially PTSD. ScienceDaily. www.sciencedaily.com/releases/2020/05/200518184914.htm. Accessed 19 June 2020.

Vastag, B. \& Mazur, B. (2020). Researchers warn Covid-19 could cause debilitating long-term illness in some patients. Washington Post. https://www.washingtonpost.com/health/could-covid-19-causelong-term-chronic-fatigue-and-illness-in-some-patients/2020/05/29/bcd5edb2-a02c-11ea-b5c9-570 a91917d8d_story.html. Accessed 19 June 2020.

Vogt, H., Hofmann, B., \& Getz, L. (2016). The new holism: P4 systems medicine and the medicalization of health and life itself. Medicine, Health Care and Philosophy, 19, 307-323.

White, P., Rickards, H., \& Zeman, A. Z. J. (2012). Time to end the distinction between mental and neurological illnesses. British Medical Journal, 344, 1-3.

Woods, S. (2015). Holism in healthcare: Patient as person. In T. Schramme \& S. Edwards (Eds.), Handbook of philosophy of medicine (pp. 1-17). New York: Springer.

World Health Organization. (2019). Constitution. Resource document. https://www.who.int/about/who-weare/constitution. Accessed 17 July 2019.

Yong, E. (2020). COVID-19 Can Last for Several Months: The disease's "long-haulers" have endured relentless waves of debilitating symptoms-and disbelief from doctors and friends. Atlantic Monthly. https://www.theatlantic.com/health/archive/2020/06/covid-19-coronaviruslongterm-symptoms-months/612679/. Accessed 19 June 2020.

Zucker, A. (1981). Holism and reductionism: A view from genetics. The Journal of Medicine and Philosophy, $6,145-163$.

Publisher's Note Springer Nature remains neutral with regard to jurisdictional claims in published maps and institutional affiliations. 